to be sure, is an interesting metamorphosis but its explanation lies in the province of historians and sociologists. It is hardly surprising that the contribution made by the Colorado scientists to the problem is worth little more than what a panel of theologians would have to say about current cosmological theories of the universe. We conclude, Dr Condon says, "that further extensive studies of UFOs probably cannot be justified in the expectation that science will be advanced thereby".

A firmer grasp of historical perspective by the project's sponsors might have attenuated the compulsion to reaffirm so foregone a conclusion. But perhaps the Colorado project, like the Apollo project, is a case of the means justifying the end and the end being justified by spin-off. After all, a great deal of incidental information has been collected in the course of the project about anomalous propagation effects and the malfunctioning of complex lens systems, while Project Blue Book, the Air Force's compilation of UFO sightings which was the forerunner to the Colorado project, has already provided astronomers with useful data for estimating social bias in the observation of meteorites.

The Colorado project is a monumental achievement, but one of perhaps misapplied ingenuity. It would doubtless be inapt to compare it with earlier centuries' attempts to calculate how many angels could balance on the point of a pin; it is more like taking a sledgehammer to crack a nut, except that the nuts will be quite immune to its impact.

\title{
Drugs on Prescription
}

In the same year that the Sainsbury Committee's recommendations for broad changes in British policy towards drugs were published, the Task Force on Prescription Drugs was established in the United States under Mr John Gardner-then Secretary of Health, Education and Welfare-to study the problems of including the cost of out-of-hospital (prescription) drugs under Medicare. The task force included Dr Philip R. Lee (Assistant Secretary for Health and Scientific Affairs), Dr Alice M. Rivlin (Assistant Secretary for Planning and Evaluation), Mr Robert M. Ball (Commissioner, Social and Rehabilitation Service), $\mathrm{Mr}$ Joseph H. Meyers (Deputy Administrator, Social and Rehabilitation Service), Mr Dean Coston (Executive Assistant to the Secretary), Mr. James F. Kelly (Assistant Secretary), Dr Herbert L. Ley, jun. (Commissioner, Food and Drug Administration), Dr William H. Stewart (Surgeon General, Public Health Service) and Dr Milton Silverman (Special Assistant to the Assistant Secretary for Health and Scientific Affairs. Since then the task force has published a number of background papers and interim reports in which recommendations are set out as to how the burden of drug costs for the elderly could be eased, and how the cost of drugs to the Federal and State Governments could be lowered. But the task force has also taken its mammoth assignment one step further; it has examined the activities of the Department of Health, Education and Welfare in the pharmaceutical field to determine what reorganization, if any, is required.

Medicare already covers almost all of the in-patient hospital expenses of the elderly, as well as a significant proportion of their expenses for physicians and other medical services. Nevertheless, as the task force has emphasized, drug expense represents the largest single personal health expenditure that the elderly must meet almost entirely from their own resources-present aid from private insurance, existing public programmes and tax relief is insufficient. In 1967, for example, prescription drugs accounted for 20 per cent of the health expenditure of older people, and in 1966 the average prescription cost for the elderly was $\$ 3.91$, compared with an average for the population as a whole of $\$ 3.43$.

As far as implementing the Medicare benefit is concerned, the task force maintains that, to start with at least, it would be desirable to provide the benefit on a less-than-comprehensive basis. It has been estimated that comprehensive coverage would be $\$ 1,600$ million, exclusive of administrative costs. Less-than-comprehensive coverage would help to reduce both the cost and the numerous complex administrative problems of the scheme. Coverage would probably be provided under the hospital insurance (Part A) Medicare programme, for under this virtually all people aged 65 or more would be automatically eligible for the new benefit.

In order to limit the scope of the drug programme, the task force suggests that the number of drugs covered could be limited to those which are important for the treatment of serious chronic illness in the elderly. On this basis, and assuming that 1971 would be the first year of operation, it is estimated that benefit payments would amount to $\$ 720$ million for the first year, with reimbursement made for about 125 million prescriptions. Assuming a $\$ 1$ co-payment, the level cost of the new benefit would be $0 \cdot 19$ per cent of taxable payroll. Alternatively, reliance could be placed on a "high-costsharing factor" whereby benefit would be paid only when a beneficiary's drug expenses exceeded a specificd, relatively high amount. The cost of this proposal would be $\$ 405$ million in the first year of operation, and reimbursement would probably be made for about 100 million claims. The level cost of the proposal would be $0 \cdot 14$ per cent of taxable payroll. Another alternativelimiting benefits to those over a certain age, for example, 70 or 72 -is considered unsuitable.

The task force suggests that responsibility for the drug bencfit should rest with the Secretary of Health, Education and Welfare, with a primary delegation of authority to the Social Security Administration. Ai a lower level of administration, the task force concludes that it would be better if the vendor-that is, community, mail-order or hospital out-patient pharmacies -rather than the beneficiary initiated claims and was reimbursed by the programme. This would enable the Social Security Administration to take advantage of advances in electronic data processing capabilities, including equipment which would permit transmittal of claims information directly from the drugstores to the agency processing the claims. 
The US pharmaceutical industry is not likely to be cheered by the suggestion that reimbursement for product cost should be based on the cost of the least expensive chemical equivalent of acceptable quality generally available on the market; that is, acquisition by generic name. The need for this is indicated by the fact that Meticorten costs $\$ 8.50$ for thirty tablets, while under its generic name of prednisone the drug is available at $\$ 2.58$ for the same number of tablets. Similarly, 100 tablets of Serpasil costs $\$ 7.06$ although it is available under the generic name of reserpine at $\$ 2.91$. Physicians will have to be urged to prescribe low-cost chemical equivalents for all beneficiaries of Federal drug programmes, and the Department of Health, Education and Welfare will have to keep physicians, vendors and the general public informed on the availability, quality and relative costs of chemical equivalents. Direct purchase of drugs by the Federal Government for Medicare beneficiaries as a means of controlling prices is not recommended. And if the vendor rather than the beneficiary were reimbursed, the task force would prefer a fixed fee approach; that is, vendors charging a fixed dispensing fee per prescription, as used by a number of State and Federal programmes. On this basis, the most feasible method of sharing the cost of the benefit with the beneficiary would be for the latter to be responsible for paying part of the cost of each prescription.

The task force has given careful consideration to the question of whether the Federal Government can exercise more effective controls on the costs of drugs supplied in the Medicare, Medicaid and Maternal and Child Health Programmes, and has recommended legislation to establish reasonable cost and charge ranges, and limits for Federal participation in reimbursement for drugs supplied under these programmes. It considers that the exclusion of certain combination products and duplicative drugs from Federal reimbursement could yield overall savings of at least 10 per cent. This is highly desirable in view of the fact that the Federal and State Governments spent $\$ 208$ on prescription drugs for welfare recipients alone in the year ending June 30, 1968. Further saving could be achieved if products were dispensed under their generic names. In this connexion the task force is confident that the Federal Government can provide adequate assurance that low-cost chemical equivalents will be of sufficiently high quality and will provide essentially the same clinical effects as drugs sold by their brand names and often at higher cost. Once it becomes possible to market chemical equivalents, the original drug product should serve as the reference product, so that any generic-name counterpart proposed for introduction would be required to match the reference product and to present clinical evidence of safety and efficacy. Any chemical equivalent not meeting one of these requirements should not be accepted for reimbursement or purchase. It is envisaged that the use of a restricted formulary could lower the cost of a drug programme. All these provisions would involve significant administrative costs. Thus it has been estimated that administrative costs would be more than $\$ 100$ million during the first year and approximately $\$ 34$ million annually after the first 5 years.

Among other things, it would be necessary to establish an expert advisory committee to advise the secre- tary on the qualification of specific drugs and drug groups for cost reimbursement. Full implementation of such provisions could not therefore be assured in less than two years after enactment of appropriate legislation.

The task force recommends that the Secretary of Heath, Education and Welfare should, after consultation with representatives of the drug industry, pharmacy, clinical medicine and consumer groups, appoint a study group to reappraise the efficiency of methods now used by the Division of Biologics Standards and the Food and Drug Administration to evaluate the safety and effectiveness of pharmaceuticals. It should also consider the feasibility of developing a registration and licensing system which would ensure that all drugs marketed in interstate commerce are produced under adequate quality control standards. It also recommends that the Social Security Administration should undertake continuing responsibility for the surveillance of drug costs, average prescription prices and drug use.

The task force is concerned that efforts should be strengthened to assure that the skills of experts both within and outside the Department of Health, Education and Welfare are used to augment the scientific capabilities of the Food and Drug Administration. This might be achieved in part by enlisting the assistance of individual scientists from health agencies within the Federal Government to serve for limited periods on tasks relevant to their research interests, or by their acceptance of ad hoc assignments for the evaluation of specific drugs. The scientific capability of the FDA's drug evaluation staff could also be enhanced by the establishment of a clinical and labora. tory facility within the FDA to concentrate on research concerned with the use, efficacy and toxicity of drugs, and the development of new methods and approaches to their evaluation. This would provide opportunities within the FDA for research and application extending from molecular pharmacology to animals testing and clinical experience.

\section{PHYSICS \\ Accelerator in Demand}

Now that construction of the $200 \mathrm{GeV}$ particle accelerator at Batavia, Illinois, is under way, everybody is rushing to join it. Two more American universities have now joined the Universities Research Association, the body which provides management for the $200 \mathrm{GeV}$ machine. The two universities, Case Western Reserve University of Cleveland, Ohio, and the State University of New York at Stony Brook, bring the total membership of URA to 50,49 of them universities in the United States.

The odd man out at the moment is the University of Toronto, the only Canadian university to join. URA so far. But a report published this week by five Canadian physicists urges a much greater participation by Canada in the building of the $200 \mathrm{GeV}$ machine. The group, under the chairmanship of Professor E. P. Hinks of Carlton. University, was given a grant by the National Research Council in the autumn of 1967 to investigate the possibility of Canadian cooperation in the project. Their report concludes that Canada should indeed support the accelerator, by providing an 